\title{
Correction to: Why Do Reoperation Rates Vary So Much After Lumpectomy for Breast Cancer? Examining the Reoperation Puzzle
}

Jeffrey Landercasper, MD

Gundersen Health System and Gundersen Medical Foundation, La Crosse, WI

\section{CORRECTION TO: ANN SURG ONCOL (2018) 25:2506-2508 HTTPS://DOI.ORG/10.1245/S10434-018-6609-0}

The title of this Editorial is corrected as reflected here. In the published editorial, the use of the affiliation Massachusetts General Hospital (MGH) as mentioned throughout the text was incorrect. Wherever stated, the following reference should have been cited:
Valero MG, Mallory MA, Losk K, et al. Surgeon variability and factors predicting for reoperation following breast-conserving surgery. Ann Surg Oncol. 2018;25:2573-8.

The journal apologizes for this error.

The original article can be found online at https://doi.org/10.1245/ s10434-018-6609-0. 